\title{
Classification of Single Line to Ground Faults on Double Circuit Transmission Line using ANN
}

\author{
Anamika Jain, A. S. Thoke, Member, IEEE and R. N. Patel, Member, IEEE
}

\begin{abstract}
This paper discusses the potential application of ANN techniques for detection of single line to ground faults and fault type classification on double circuit transmission lines with remote end infeed. Distance protection of double circuit transmission lines has been a very challenging task. The problems arise principally as a result of the mutual coupling between the two circuits under different fault conditions. An accurate algorithm for fault detection and classification of single line-to-ground faults (A1N, A2N, B1N, B2N, C1N \& C2N) in double circuit transmission line considering the effects of mutual coupling, high fault resistance, varying fault location, fault inception angle and remote source infeed is presented using feed forward neural network (FFNN) algorithm. The algorithm employs the fundamental components of voltage and current signals. This technique neither requires communication link to retrieve the remote end data nor zero sequence current compensation for healthy phases are required. This is a major advantage of the proposed algorithm for protection of double circuit line fed from both the ends. Results of study on a $220 \mathrm{kV}$ transmission line are presented as an illustration. Simulation results indicate that algorithm is immune to the effect of mutual coupling, fault type, fault inception angle, fault resistance, fault location and remote end infeed.
\end{abstract}

Index Terms - Artificial neural network, Double circuit transmission line, Fault detection \& classification, High impedance fault, Single line-to-ground fault.

\section{INTRODUCTION}

Double circuit transmission lines have been extensively utilized in modern power systems to enhance power transfer, reliability and security for the transmission of electrical energy. The different possible configurations of double circuit lines combined with the effect of mutual coupling make their protection a challenging problem. The zero sequence mutual impedance can be as high as $50-70 \%$ of the self-impedance. Thus mutual coupling particularly under earth faults pose difficulties for conventional distance protection schemes. The main source of errors in fault location results from remote-end infeed effect under resistive faults. As a result, the measured impedance is no longer a geometrical measure of a fault distance. Fault resistance is seen as certain apparent impedance and in consequence the measured reactance consists of the reactance of a line up to the fault point and the reactance component contained in the

Manuscript received December 20, 2008.

Anamika Jain is with the Department of Electrical Engineering, N.I.T. Raipur, C.G. India.

A.S.Thoke is with the Department of Electrical Engineering, N.I.T. Raipur, C.G. India

R.N. Patel is with the Department of Electrical and Electronics Engineering, SSCET, Bhillai, C.G. (Corresponding author: Phone: +91-9827494379). measured fault resistance. It should be noted that the aforementioned problems are particularly endemic when there is an earth fault. The vast majority of faults (over 90\%) are of the single line to ground type.

Artificial Neural Network (ANN) is useful for power system applications because they can be trained with off-line data [1]. The specialty of ANN based distance protection is that it does not explicitly use the impedance information as the basis of information rather it learns from the examples presented to it during training. ANNs possess excellent features such as generalization capability, noise immunity, robustness and fault tolerance. Artificial neural network (ANN) has emerged as a powerful tool for different power system application in recent years because of its pattern recognition, generalization and learning ability. Various ANN-based techniques have been proposed for transmission line protection in past [2]-[14]. Bouthiba [2] proposed and tested ANN based algorithm to detect and locate the fault of the double end fed single circuit transmission line for only phase to ground fault. Zadeh and Aghaebrahimi [3] proposed and tested ANN based approach to classify and locate the fault of a single end fed medium voltage cables. Pasand and Zadeh [4] proposed and tested ANN based double end fed single circuit transmission line fault detector and phase selector for all types of faults. D. V. Coury et al. developed a complete protection scheme for a single circuit transmission line [5]. A.G. Jongepier et al. [6] present an adaptive distance protection of double circuit line using zero sequence thevenin equivalent impedance and compensation factor for mutual coupling to increase the reach \& selectivity of relay [6], however it requires communication link to retrieve remote-end data. L. S. Martins et al. [7] used the Clarke-Concordia transformation, Eigen value approach and $\mathrm{NN}$ to locate the fault distance of double circuit line [7], but it does not classify the faults. Kohonen network is used to improve the accuracy of distance relay for single line to ground fault on a single circuit line in [8], faults on circuit-2 line are not considered and it does not classify the faults. Cascade correlation algorithm based ANN is presented for fault location and fault resistance determination in [9], but it does not classify the faults. Back propagation method based on Levenberg-Marquardt optimization technique is used to locate the faults in [10], but it does not classify the faults. The work presented in [11] deals with the compensation of fault resistance using adaptive techniques with the help of an ANN, effect of other factors as mentioned below are not considered. A single line to ground fault location method employing wavelet fuzzy neural network to use post-fault transient and steady-state measurements in the distribution lines of an industrial system is proposed in [12], it does not classify the 
faults. Anamika Jain et al. report single circuit transmission line fault detection, faulty phase selection and fault location using ANN [13]. Fault classification of single circuit lines using ANN is presented in [14]. Reference [15] discusses ANN based technique for fault classification of line to ground fault on only one phase (A1N \& A2N) of double circuit transmission line. All the above techniques require either communication link between the two ends of line and/or locate the fault but do not classify the fault type, whereas others are for single circuit transmission lines only.

In this paper an accurate algorithm for fault detection and classification of line-to-ground fault on all the three phases of both the circuit of double circuit transmission line i.e. A1N, $\mathrm{A} 2 \mathrm{~N}, \mathrm{~B} 1 \mathrm{~N}, \mathrm{~B} 2 \mathrm{~N}, \mathrm{C} 1 \mathrm{~N} \& \mathrm{C} 2 \mathrm{~N}$, considering the effects of mutual coupling, high fault resistance, varying fault location, fault inception angle and remote source infeed is presented using feed forward neural network algorithm. The algorithm employs the fundamental components of voltage and current signals. This technique does not require communication link to retrieve the remote end data and nor zero sequence current compensation for healthy phases. Simulation results indicate that algorithm is immune to the effect of mutual coupling, fault type, fault inception angle, fault resistance, fault location and remote end infeed. A $220 \mathrm{kV}$ parallel transmission line configuration is simulated using MATLAB $^{\circledR}$ software [16].

\section{FAUlt DeteCtion \& ClassifiCATION AlgORITHM}

The basic points of the procedure used to implement a neural network in the fault detection and classification algorithm in double circuit transmission line is described below.

\section{A. Selecting the Right Architecture}

One factor in determining the right size and structure for the network is the number of inputs and outputs that it must have. The lower the number of inputs, the smaller the network can be. However, sufficient input data to characterize the problem must be ensured. To enable the method to be implemented in both fault detection and classification devices and centralised systems, only the magnitudes recorded at one end of the line are used. The inputs to distance relay are mainly the voltages and currents. Hence the network inputs chosen here are the magnitudes of the fundamental components $(50 \mathrm{~Hz})$ of three phase voltages and six currents measured at the relay location recorded at one end of the line. As the basic task of fault classification is to determine the type of fault alongwith the phase, seven outputs corresponding to six phases and neutral were considered as outputs provided by the network. Thus the network input $\mathbf{X}$ and the output $\mathbf{Y}$ is:

$$
\begin{aligned}
& \mathbf{X}=\left[V_{a}, V_{b}, V_{c}, I_{a 1}, I_{b 1}, I_{c 1}, I_{a 2}, I_{b 2}, I_{c 2}\right] \\
& Y=[A 1, B 1, C 1, A 2, B 2, C 2, N]
\end{aligned}
$$

Once it was decided how many inputs and outputs the network should have, the number of layers and the number of neurons per layer were considered. After several trials, it was decided to use a neural network with three layers, with nine neurons in the input layer, thirty neurons in the hidden layer and seven in the output layer, as shown in Fig. 1.

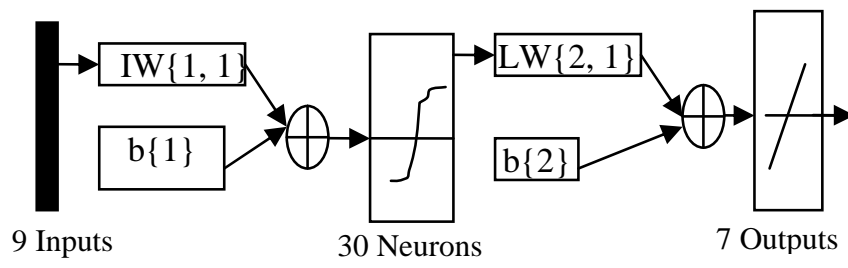

Fig. 1. Structure of ANN based fault detector and classifier

The final determination of the neural network requires the relevant transfer functions to be established. After analyzing various possible combinations of transfer functions used, such as logsig, tansig and linear functions, the tansig function was chosen as transfer function for the hidden layer, and the purelin function in the output layer.

\section{B. Learning Rule Selection}

The back-propagation learning rule is used in perhaps $80-90 \%$ of practical applications. Improvement techniques can be used to make back-propagation more reliable and faster. The back-propagation learning rule can be used to adjust the weights and biases of networks to minimize the sum-squared error of the network. This is done by continually changing the values of the network weights and biases in the direction of steepest descent with respect to error. As the simple back-propagation method is slow because it requires small learning rates for stable learning, improvement techniques such as momentum and adaptive learning rate or an alternative method to gradient descent, Levenberg-Marquardt optimisation, can be used. Various techniques were applied to the different network architectures tested, and it was concluded that the most suitable training method for the architecture selected was based on the Levenberg-Marquardt optimization technique.

\section{Training Process}

In order to train the network, a suitable number of representative examples of the relevant phenomenon must be selected so that the network can learn the fundamental characteristics of the problem and once the training is completed, provide correct results in new situations not envisaged during training. The system studied is composed of $220 \mathrm{KV}$ double circuit transmission line $100 \mathrm{~km}$ in length, connected to sources at each end, as shown in Fig. 2 [15]. Short circuit capacity of the equivalent thevenin sources on two sides of the line is considered to be $1.25 \mathrm{GVA}$. Source to line impedance ratio is 0.5 and $\mathrm{X} / \mathrm{R}$ is 10 . The transmission line is simulated using distributed parameter line model as shown in Fig.3. Double circuit transmission line parameters are shown in Table I.

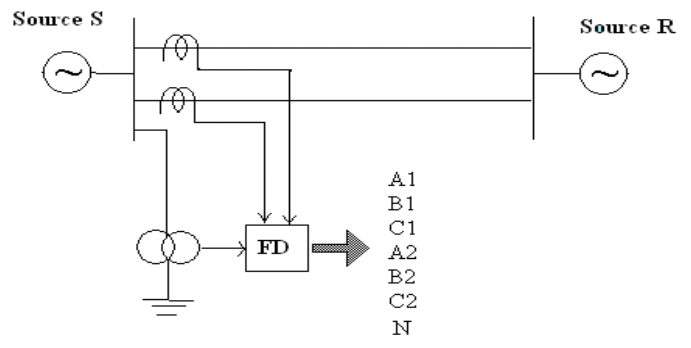

Fig. 2. Power System under study 
TABLE I DOUBLE CIRCUIT LINE PARAMETER

\begin{tabular}{|c|c|}
\hline Positive sequence resistance $\mathrm{R} 1, \Omega / \mathrm{KM}$ & 0.01809 \\
\hline Zero sequence resistance $\mathrm{R} 0, \Omega / \mathrm{KM}$ & 0.2188 \\
\hline Zero sequence mutual resistance $\mathrm{R} 0 \mathrm{~m}, \Omega / \mathrm{KM}$ & 0.20052 \\
\hline Positive sequence inductance $\mathrm{L} 1, \mathrm{H} / \mathrm{KM}$ & 0.00092974 \\
\hline Zero sequence inductance $\mathrm{L} 0, \mathrm{H} / \mathrm{KM}$ & 0.0032829 \\
\hline Zero sequence mutual inductance $\mathrm{L} 0 \mathrm{~m}, \mathrm{H} / \mathrm{KM}$ & 0.0020802 \\
\hline Positive sequence capacitance $\mathrm{C} 1, \mathrm{~F} / \mathrm{KM}$ & $1.2571 \mathrm{e}-008$ \\
\hline Zero sequence capacitance $\mathrm{C} 0, \mathrm{~F} / \mathrm{KM}$ & $7.8555 \mathrm{e}-009$ \\
\hline Zero sequence mutual capacitance $\mathrm{C} 0 \mathrm{~m}, \mathrm{~F} / \mathrm{KM}$ & $-2.0444 \mathrm{e}-009$ \\
\hline
\end{tabular}

TABLE II PATTERNS GENERATION

\begin{tabular}{|c|c|}
\hline Parameter & Set value \\
\hline Fault type & $\mathrm{A} 1 \mathrm{G}, \mathrm{A} 2 \mathrm{G}, \mathrm{B} 1 \mathrm{G}, \mathrm{B} 2 \mathrm{G}, \mathrm{C} 1 \mathrm{G}$ and $\mathrm{C} 2 \mathrm{G}$ \\
\hline Fault location $\mathrm{Lf}(\mathrm{km})$ & $0,10,20,30, \ldots 80$ and $90 \mathrm{~km}$ \\
\hline Fault inception angle & $0 \& 90 \mathrm{deg}$ \\
\hline Fault resistance & 0,50 and $100 \Omega$ \\
\hline
\end{tabular}

Fig. 4 shows the voltage and current waveforms when an 'A1'-phase to ground fault occurs at $30 \mathrm{KM}$ from end SS-1 on circuit 1 of the configuration shown in Fig. 3 at $60 \mathrm{~ms}$ with zero fault resistance and zero degree fault inception angle. As expected, a current is also induced in the 'A2'-phase of healthy circuit 2 due to the mutual coupling between the two circuits. Matlab ${ }^{\circledR}$ simulates each type of fault $(A 1 G, A 2 G$, $\mathrm{B} 1 \mathrm{G}, \mathrm{B} 2 \mathrm{G}, \mathrm{C} 1 \mathrm{G}$ and $\mathrm{C} 2 \mathrm{G}$ ) at different fault locations between $0-100 \%$ with high path fault resistances between $0-100 \Omega$ and fault inception angles $0 \& 90^{\circ}$ as shown below in Table II. Further, preprocessing is useful method that significantly reduces the size of the neural network and improves the performance and speed of training process [17]. Three phase voltages and six current input signals were sampled at a sampling frequency of $1 \mathrm{kHz}$ and further processed by simple 2nd-order low-pass Butterworth filter with cut-off frequency of $400 \mathrm{~Hz}$. Subsequently, one full cycle Discrete Fourier transform is used to calculate the fundamental components of voltage and current. The input signals were normalized in order to reach the ANN input level $( \pm 1)[16]$. The total number of fault simulated are $6 \times 10 \times 2 \times 3=360$ and from each fault cases ten numbers of post fault samples has been extracted to form the data set for neural network. Total 40 samples during no fault are also collected. Thus the total number of patterns generated for training, testing and validation are 3640 .

The next step is to divide the data up into training, validation and test subsets. One fourth of the data for the validation set, one fourth for the test set and one half for the training set has been used. The data sets were picked as equally spaced points throughout the original data. The root mean square error of the ANN based Fault Detect or and $\mathrm{Cl}$ assifier with the preprocessed data sets is shown in Fig. 5. It has been found that a single hidden layer network with 30 neurons in hidden layer and 7 neuron in output layer (9-30-7) is capable of minimizing the Mean Square Error (MSE) to a final value of 0.000507653 . This learning strategy converges quickly.

\section{Test Results of ANN BASEd FAult Detector AND CLASSIFIER}

ANN based Fault detector and Classifier is extensively tested using independent data sets consisting of fault samples never used previously in training. With different faults of the validation/test data set, fault type, fault location and fault inception angle were changed to investigate the effects of these factors on the performance of the proposed ANN based Fault detector and Classifier. Extreme cases like faults near the protection zone boundary including fault resistance were also included in the validation data set. The network was tested and validated by presenting 180 different single line to ground faults cases with varying fault locations (Lf), fault inception angles (Фi) and fault resistance (Rf). All 180 faults cases are correctly classified in less than one cycle time.

The proposed ANN based Fault detector and Classifier results for few faults with different system conditions are presented in Table III. The performance of a trained network can be measured to some extent by the errors on the training, validation and test sets, but it is often useful to investigate the network response in more detail. One option is to perform a regression analysis between the network response and the corresponding targets. The routine "postreg" of neural network toolbox of Matlab ${ }^{\circledR} 7.01$ is used to perform this analysis. Here we pass the network output and the corresponding targets to postreg. It returns three parameters. The first two, $\mathrm{m}$ and $\mathrm{b}$, correspond to the slope and the $y$-intercept of the best linear regression relating targets to network outputs. If we had a perfect fit (outputs exactly equal to targets), the slope would be 1 , and the y-intercept would be 0 . The third variable returned by "postreg" is the correlation coefficient (R-value) between the outputs and targets. It is a measure of how well the variation in the output is explained by the targets. If this number is equal to 1 , then there is perfect correlation between targets and outputs.

A linear regression analysis between the network outputs and the corresponding targets has been done for the entire data set obtained through the network training, validation and test and shown in the following Figs. 6-12. The network outputs are plotted versus the targets as open circles. The best linear fit is indicated by a dashed line. The perfect fit (output equal to targets) is indicated by the solid line. In the following figures, it is difficult to distinguish the best linear fit line from the perfect fit line, because the fit is so good.

A linear regression analysis between the network outputs and the corresponding targets has been done for the entire data set obtained through the network training, validation and test and shown in the following Figs. 6-12. The network outputs are plotted versus the targets as open circles. The best linear fit is indicated by a dashed line. The perfect fit (output equal to targets) is indicated by the solid line. In the following figures, it is difficult to distinguish the best linear fit line from the perfect fit line, because the fit is so good.

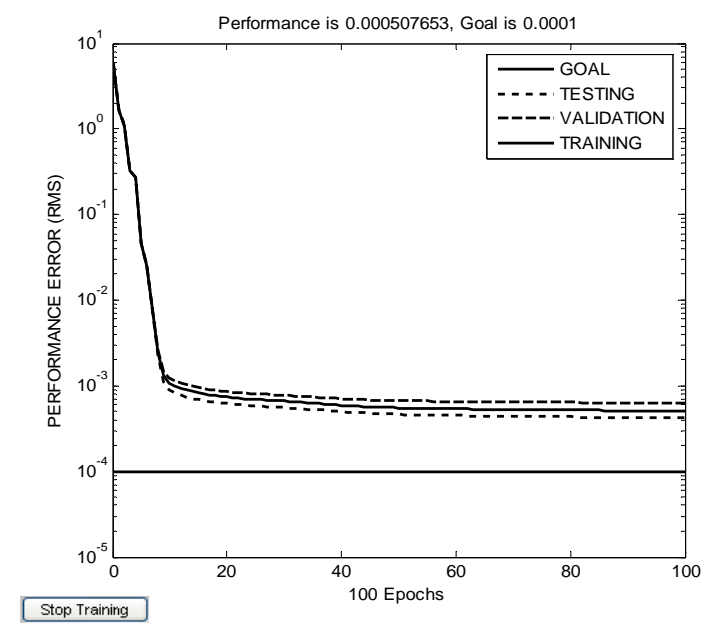


Fig. 5. Training figure obtained with Levenberg-Marquardt algorithm

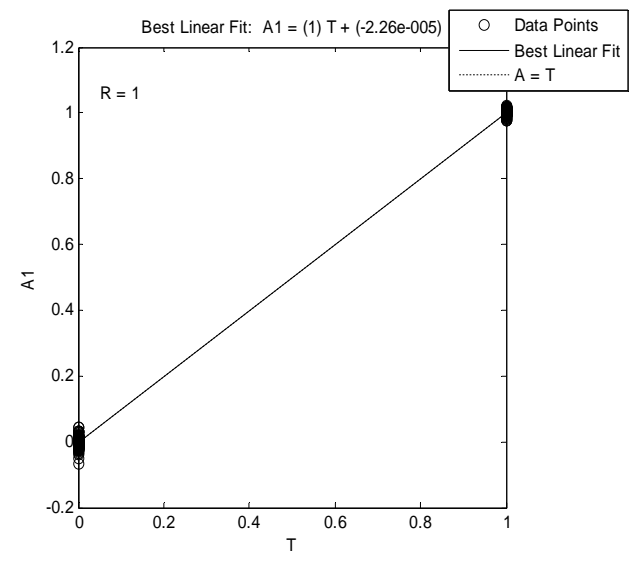

Fig. 6. Regression analysis of output "A1"

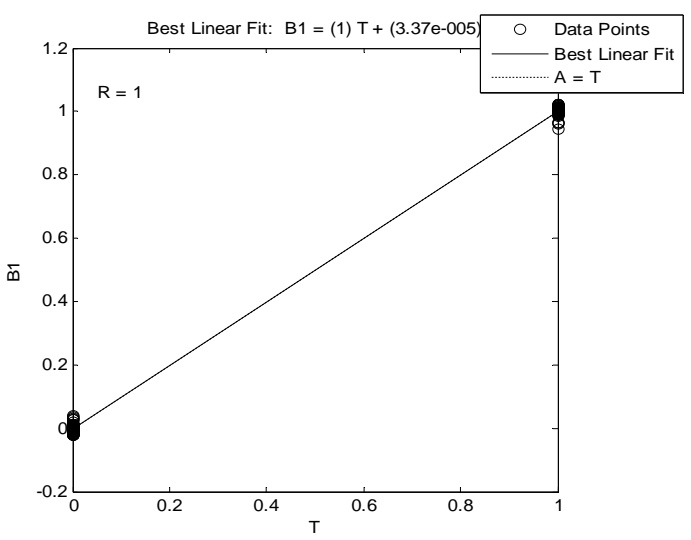

Fig. 7. Regression analysis of output "B1"

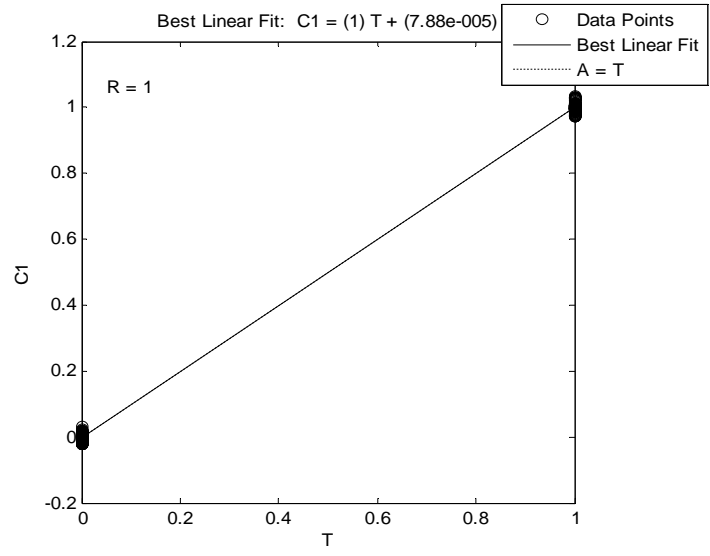

Fig. 8. Regression analysis of output " $\mathrm{C} 1$ "

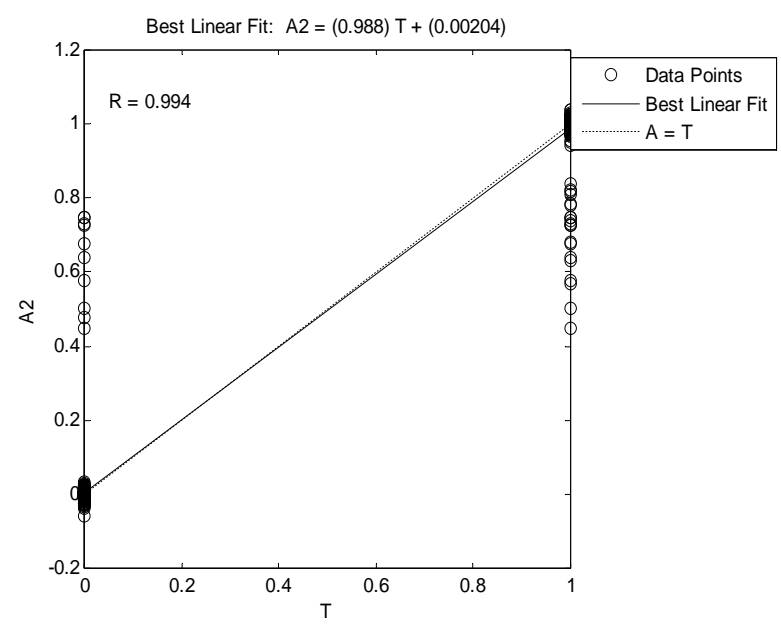

Fig. 9. Regression analysis of output "A2"

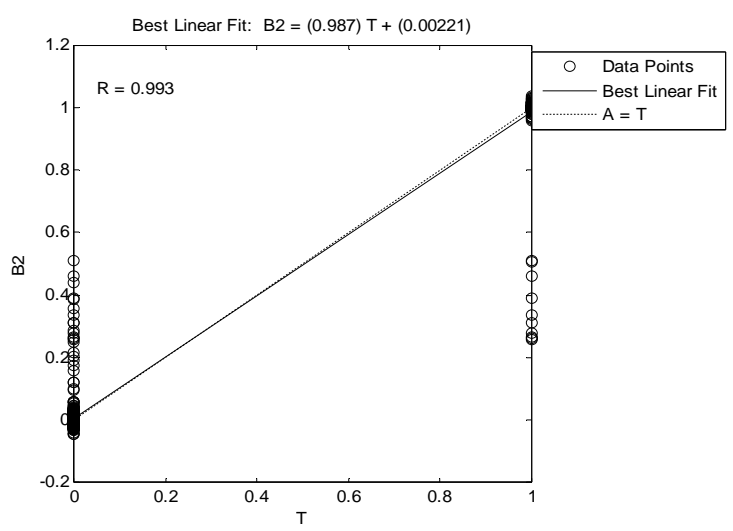

Fig. 10. Regression analysis of output "B2"

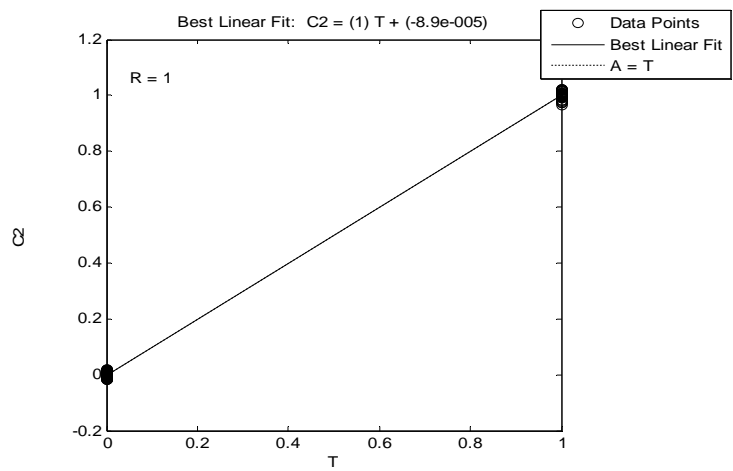

Fig. 11. Regression analysis of output "C2"

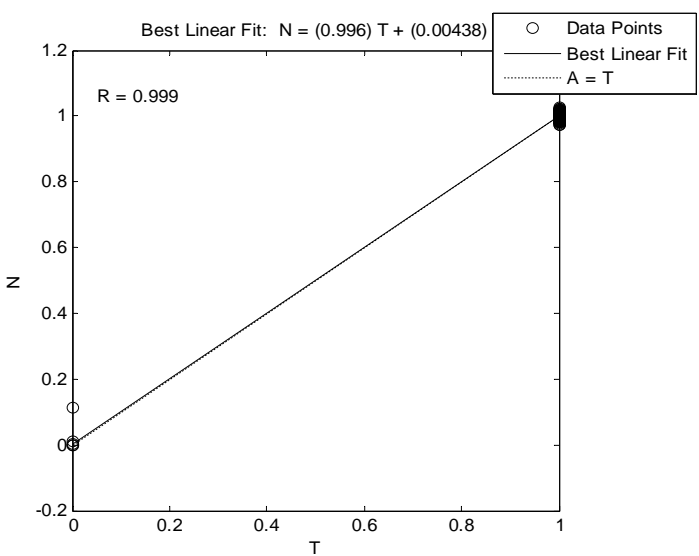

Fig. 12. Regression analysis of output "N" 


\section{CONCLUSIONS}

A feed-forward neural network structure using Marquardt Levenberg algorithm is presented for fault detection, classification technique for double-circuit line protection under single line to ground fault considering the effects of mutual coupling, high fault resistance, varying fault location, fault inception angle and remote source infeed. The algorithm employs the fundamental components of three line voltages and the six line currents of the two parallel lines at one end only. Remote end data are not required. The performance of the proposed scheme has been investigated by a number of off-line tests. The complexity of the possible types of faults (A1G, A2G, B1G, B2G, C1G and $\mathrm{C} 2 \mathrm{G}$ ), fault locations (0-100\%), high path fault resistances (0-100 $\Omega$ ), fault inception angles $\left(0 \& 90^{\circ}\right)$, mutual coupling effects and remote end in-feed are solved. The Simulation results show that single phase-to-ground faults can be correctly detected and classified after one cycle after the inception of fault. The algorithm is immune to the effects of remote end infeed, fault locations, mutual coupling, fault inception angle and fault resistances. The proposed scheme allows the protection engineers to increase the reach setting i.e. a greater portion of line length can be protected as compared to earlier techniques. The technique does not require communication link to retrieve the remote-end data and the zero sequence current compensation for healthy phases are also not required.

\section{REFERENCES}

[1] M. Kezunoic, "A survey of neural net application to protective relaying and fault analysis", Eng. Int. Sys., vol.5, No. 4, Dec. 1997, pp. 185-192.

[2] Tahar Bouthiba, "Fault location in EHV transmission lines using artificial neural networks", Int. J. Appl. Math. Comput. Sci., 2004, vol. 14 , No. 1, pp. 69-78

[3] H. Khorashadi-Zadeh, M. R. Aghaebrahimi, "A novel approach to fault classification and fault location for medium voltage cables based on artificial neural network", International journal of computational intelligence, vol. 2, No. 1, 2005, pp. 1304-2386.

[4] M.Sanaye-Pasand, H. Khorashadi-Zadeh, "Transmission line fault detection \& phase selection using ANN", International Conference on Power Systems Transients - IPST 2003 in New Orleans, USA.

[5] D. V. Coury \& D.C. Jorge, "Artificial neural network approach to distance protection of transmission lines", IEEE Trans. on Power Delivery, vol. 13, No. 1, 1998, pp. 102-108.

[6] A.G. Jongepier and L. Van Der Sluis, "Adaptive distance protection of double circuit lines using artificial neural networks", IEEE Transactions on Power Delivery, vol. 12 No.1, January 1997, pp. 97-105.

[7] L. Sousa Martins, J.F. Martins, V. Farnao Piers, and C.M Alegria, "A neural space vector fault location for parallel double-circuit distribution lines", Electrical Power and Energy Systems Journal, vol. 27, 2005, pp. 225-231.

[8] Srdjan Skok, Ante Marusic, Sejid Tesnjak, and Lvica Pevik, "Double-circuit line adaptive protection based on Kohonen neural network considering different operation and switching modes", Power Engineering 2002 Large Engineering Systems Conference on LESCOPE, vol. 2, 2002, pp. $153-157$.

[9] G.K. Purushothama, A.U. Narendranath, D. Thukaram, and K. Parthasarathy, "ANN applications in fault locators", Electrical Power and Energy Systems Journal, vol. 23, 2001, pp. 491-506.
[10] A.J. Mazon, I. Zamora, J. F. Minambres, M.A. Zorrozua, J.J. Barandiaran, and K. Sagastabeitia, "A new approach to fault location in two-terminal transmission lines using artificial neural networks", Electric Power Systems Research Journal, vol. 56, 2000, pp. 261-266

[11] S.A. Khaparde, N. Warke, and S.H. Agarwal, "An adaptive approach in distance protection using an artificial neural network" Electric Power Systems Research Journal, vol. 37, Issue 1, April 1996, pp. 39-46.

[12] Fan Chunju, K.K. Li, W.L. Chan, Yu Weiyong, and Zhang Zhaoning, "Application of wavelet fuzzy neural network in locating single line to ground fault (SLG) in distribution lines", Electrical Power \& Energy System Journal, vol. 29, Issue 6, July 2007, pp. 497-502.

[13] Anamika Jain, V.S. Kale, and A.S. Thoke, "Application of artificial neural networks to transmission line faulty phase selection and fault distance location", Proceedings of the IASTED International conference "Energy and Power System", Chiang Mai, Thailand, Mar. 29-31, 2006, paper No. 526-803, pp. 262-267.

[14] T. Dalstain, and B. Kulicke, "Neural network-approach to fault classification for high speed protective relaying ", IEEE Trans. on Power Delivery, vol. 10, No. 2, Apr. 1995, pp. 1002-1011.

[15] Anamika Jain, A.S. Thoke, and R.N. Patel, "Fault classification of double circuit transmission line using artificial neural network", International Journal of Electrical Systems Science and Engineering, vol. 1, No. 4, Fall 2008, pp. 230-235.

[16] R. Patel and K.V. Pagalthivarthi, "MATLAB-based modelling of power system components in transient stability analysis", International Journal of Modelling and Simulation, vol. 25, No. 1, 2005, pp. 43-50.

[17] H. Demuth \& M Beale, Neural Network -toolbox - for Use with Matlab ${ }^{\circledR}$. Available: http://www.mathworks.com

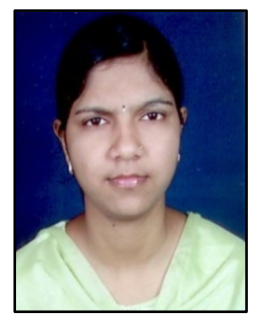

Anamika Jain did her B.E. in Electrical Engineering from RGPV Bhopal in year 2002. She acquired her M.Tech in Integrated Power Systems from V.N.I.T., Nagpur, India in 2006. She had worked as Assistant Engineer in the Chhattisgarh State Electricity Board, Raipur, C.G, India from Jul'2004 to Feb'2009. Presently she is working as Lecturer in Electrical engineering at National Institute of Technology, Raipur, C.G, India. Currently she is pursuing research work leading to $\mathrm{PhD}$. Her research interest is in application of ANN to Power System protection.

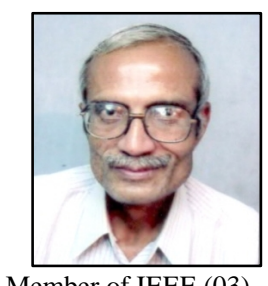

Dr. A.S. Thoke did his B.E., M. Tech. \& PhD. all in Electrical Engineering. He is a Professor in Electrical Engineering Department at National Institute of Technology, Raipur (C.G.), India. Dr. Thoke has a teaching \& research experience of 32 years. His fields of interest are application of Artificial Intelligence to Power system with particular interest in protection. Dr. Thoke is

Member of IEEE (03).

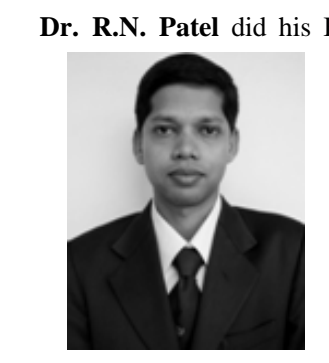

B.E. in Electrical Engineering in year 1997. He acquired his M. Tech. and Ph. D. (Power Systems) degrees from IIT Delhi in years 1998 and 2002 respectively. He has worked as a faculty of Electrical Engineering in IIT Roorkee during year 2003-2006. Presently he is working with the Electrical Engineering department at SSCET, Bhilai, India. His main fields of interest are: Power System dynamics and Stability, Modelling of Power Systems and AI applications to Power Systems. Dr. Patel has more than 50 publications in various International Journals and Conferences. Dr. Patel is Member of IEEE (09) 


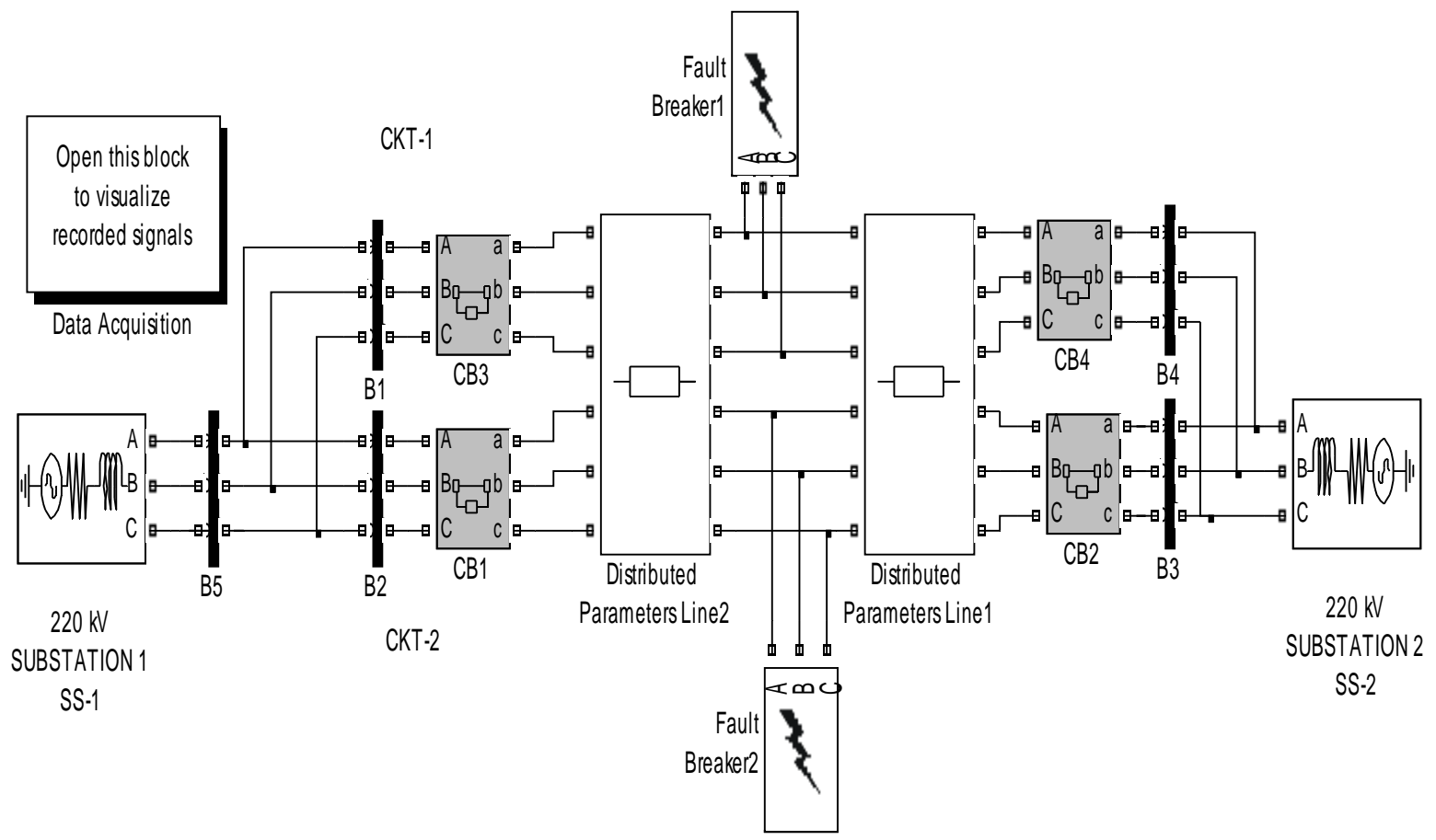

Fig. 3. Power system model simulated in MATLAB Simulink software
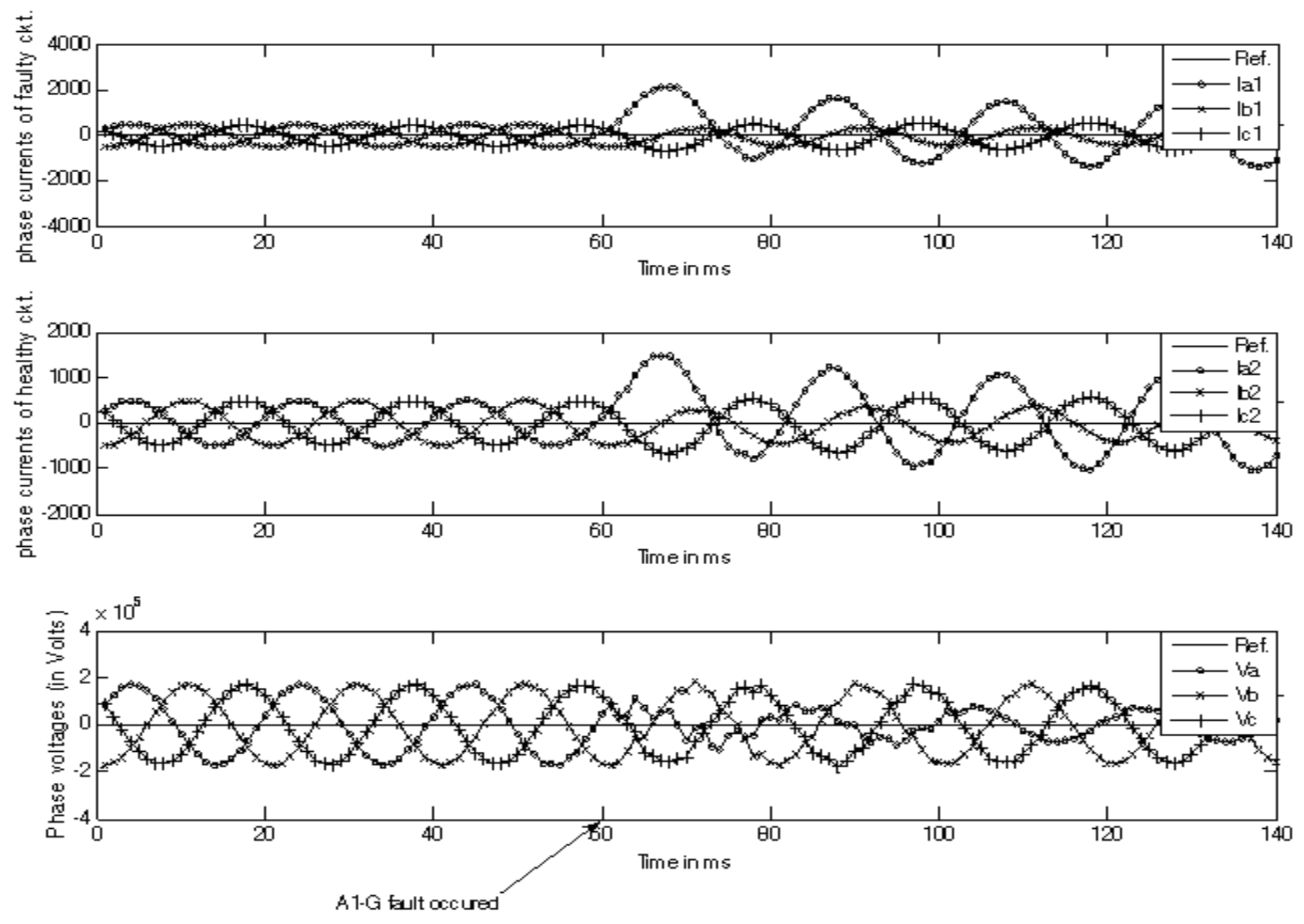

Fig. 4. Phase Voltage \& phase currents during SLG fault 
International Journal of Computer and Electrical Engineering, Vol. 1, No. 2, June 2009 1793-8163

\begin{tabular}{|c|c|c|c|c|c|c|c|c|c|c|}
\hline type & $\begin{array}{c}\text { Inception } \\
\text { angle } \\
\Phi \mathrm{i}\left({ }^{\circ}\right)\end{array}$ & $\begin{array}{c}\text { Resistance } \\
\mathrm{Rf}(\Omega)\end{array}$ & $\begin{array}{c}\text { Location } \\
\mathrm{Lf} \\
(\mathrm{KM})\end{array}$ & $\mathrm{A} 1$ & $\mathrm{~B} 1$ & $\mathrm{C} 1$ & $\mathrm{~A} 2$ & $\mathrm{~B} 2$ & $\mathrm{C} 2$ & $\mathrm{~N}$ \\
\hline $\mathrm{A} 1 \mathrm{G}$ & 90 & 100 & 1 & 0.98479 & 0.0047454 & -0.0010243 & 0.019869 & -0.0063293 & 0.0028704 & 1.005 \\
\hline A1G & 0 & 0 & 30 & 1.0032 & -0.0017265 & -0.00033085 & 0.0014524 & -0.0010077 & 0.0006014 & 1.002 \\
\hline A2G & 0 & 50 & 40 & 0.0032544 & 0.0012981 & 0.0014484 & 0.99697 & 0.00027011 & -0.0018129 & 1.0015 \\
\hline A2G & 90 & 100 & 20 & 0.0063698 & -0.0010541 & 0.00022668 & 1.0049 & -0.0038093 & -0.0029386 & 1.0037 \\
\hline B1G & 0 & 0 & 50 & 0.0002122 & 1.0025 & 0.0044866 & -0.0045013 & 0.0019069 & 0.0011017 & 1.0057 \\
\hline B1G & 90 & 50 & 60 & 0.0018889 & 0.99755 & -0.0020273 & -0.0021138 & 0.003918 & 0.00040369 & 0.9998 \\
\hline B2G & 0 & 100 & 70 & 0.0014458 & -0.02025 & 0.0016853 & 0.0014064 & 1.0105 & -0.00025897 & 0.99457 \\
\hline B2G & 90 & 50 & 90 & -0.0026176 & -0.008789 & 0.0032397 & -0.0035296 & 1.0167 & 0.0047349 & 1.0099 \\
\hline C1G & 0 & 0 & 1 & 0.00057295 & 0.00012832 & 1.0008 & -0.0022666 & 0.0017354 & -0.0017539 & 0.99888 \\
\hline C1G & 90 & 50 & 80 & -0.0020437 & -0.0020389 & 1.0294 & 0.00048041 & -0.0094879 & -0.018505 & 0.99762 \\
\hline C2G & 90 & 100 & 10 & 0.0014957 & 0.00052057 & 0.004916 & -0.00075734 & -0.0062395 & 1.0029 & 1.0028 \\
\hline C2G & 0 & 50 & 50 & 0.0029022 & -0.0012105 & -0.0046847 & 0.0030638 & 0.00024216 & 1.0037 & 1.0039 \\
\hline
\end{tabular}

